\title{
A Hardware Implementation of LUO Converter fed BLDC Motor Drive for Power Quality Improvement
}

\section{S. Arunkumar}

\begin{abstract}
The extensive coverage of solar PV systems have revolutionized the application of power electronics concept in agricultural field. In present scenario, solar based pumping electric motor are being used in more common for ground water based irrigation purpose. Since the output of solar system is DC and highly variant, we require an inverter and suitable controller to do the required supply conversions and maximum power tracking respectively. In conventional systems, a diode or thyristor based inverter fed induction motors are used which is the reason for low power factor at supply mains and low efficiency at load side. In order to overcome this issue, the idea proposed is to employ a BLDC motor fed by LUO converter and two level inverter. Owing to the nature of performance enhancement of LUO converter and BLDC motor, this arrangement provide improved power quality at supply mains, reduced torque ripple end high efficiency.
\end{abstract}

Index Terms - BLDC Motor, Power Quality, LUO Converter, Power Factor Correction, Torque Ripple, Diode bridge Rectifier, Solar PV, Irrigation.

\section{INTRODUCTION}

Household appliances like washing machine, refrigerator, air conditioners, vacuum cleaners, freezers etc., are expected to be one of the fastest growing end products in the market over the last few years. In these appliances, conventionally DC motor techniques are used. But it suffers from lot of drawbacks like sparking in brushes, requirement for frequent maintenance. Adding to that, it requires DC input power supply which is obtained with the help of batteries and AC-DC converters. This increases the complexity as well as the overall cost of the drive. So DC motors are being replaced with the help of AC induction motors including, split phase, capacitor-start and capacitor-start and run types, as well as universal type motors. These motors are operated as constant speed motor with the help of AC power supplies. Now consumers are moving to renewable energy based drives because of its characteristics like variable speed operations, higher efficiency, lower cost, better performance, lower acoustic noise and more convenient features. The better choice for these consumer requirements is Brushless DC Motors (BLDC).

Brushless DC motors are the kind of permanent magnet DC motors in which permanent magnet is on the rotors and windings are placed on the stator. As the name indicates it is free from commutator brush arrangement, instead the motor is commutated electronically with the help of power electronic switches. So BLDC motors can be called as electronically commutated motors. The BLDC motor windings are connected with the two level inverter. The inverter switches are commutated with the help of rotor positions that is sensed with the help of hall sensors. So based on the rotor position sensed at each instant, the switches are commutated, one from the upper leg and another from the lower leg of the inverter. Each switch conducts for $120^{\circ}$ duration and each switch pair conducts for $60^{\circ}$ duration. For one full revolution of the motor, six commutation sequences exist. Because of this concept, the BLDC motors have good running performance.

In practical BLDC drives, there exists torque pulsations due to non-ideal back EMF waveforms, commutation torque ripple and Pulse Width Modulation (PWM) switching. Ripples in torque are caused by the mismatches between the current and applied emf with the motor dynamics. At any time, only two of three phases are active and one is in inactive state. The freewheeling action of diode in inactive phases is also responsible for the ripple produced in torque. This torque ripple produces undesirable noise and degrades the speed control nature at low speeds especially. This is one of the main disadvantages of the BLDC drive. Also, the frontend converter used will affect the power supply quality. $\{1-2]$.

Researchers have analyzed the influence of three different PWM techniques/patterns namely H_PWM-L_ON, H_ONL_PWM and PWM_ON on the commutation torque ripple in the BLDC motor fed with trapezoidal back EMF. In the first scheme, the upper switches are operated with PWM scheme and lower switches are operated with ON condition and vice-versa in second scheme. In the third scheme, both the switches are operated in the PWM method. They have compared the results obtained with these three PWM schemes and concluded that, in the first scheme the torque ripple due to upper switching commutation is smaller than the lower switch commutation as well as in the second scheme the torque ripple in the lower scheme is lower than the upper switch scheme. In the third scheme, the torque ripple is found to be constant and minimum [3].

Generally BLDC motor have two operating regions namely conduction region and commutation region. In the conduction region,based on the reference of rotor position, two stator windings are conducted. In commutation region, transition occurs from one switch pair into another switch pair which results in excitation of another combination of two stator windings. It results in continuous motion of

\footnotetext{
Revised Manuscript Received on 14 August, 2019.

S. Arunkumar, Assistant Professor, Department of EEE, Kumaraguru College of Technology, Coimbatore, Tamilnadu, India.(Email: akumar5989@gmail.com)
} 


\section{A HARDWARE IMPLEMENTATION OF LUO CONVERTER FED BLDC MOTOR DRIVE FOR POWER QUALITY IMPROVEMENT}

motor [4]. The torque ripples are produced in majority on this commutation region. Because, without the knowledge of the shape of the back EMF waveform, the switches are commutated. This problem is resolved with a novel automatic current control method in which iron \& stray losses in the windings are neglected and assumed that the three phase stator winding are symmetrical. The duty cycle of pulse width modulation (PWM) is regulated in real time by measuring the wave function of back EMF. The diode freewheeling action in inactive phase is eliminated with this PWM scheme. But this method hold good results only on high speed condition, where significant errors are introduced at lower speeds [5].

Another major issue in the BLDC motor drive is reduced power factor at supply mains, whose contributor is the front end converter design. Initially diode bridge rectifier coupled with high value DC link capacitors are used as frontend converter. Now-a-days they are replaced with the help of bridgeless type converters like Bridgeless sepic and cuk converters. But these two converters have high switching loss and high switching stress in the converter switches [6]. Later Bridgeless Type III converters are proposed for domestic applications which have minimum number of switches, so that the losses in the switches are reduced and power quality at supply mains is also increased. But in this method the stator current have significant amount of harmonics [7]. TheType III Cuk converter was replaced with the help of bridgeless buck boost converter operated in discontinuous inductor current mode. This drive was evaluated for a wide range of speed control and has resulted in improved power quality at supply mains. The voltage and current stress in the switches are also reduced. But this method doesn't provide the necessary protection to limit the inrush current during starting and overloading conditions [8].

\section{PROPOSED SCHEME}

In the proposed scheme, LUO converter is used as front end converter for PV based BLDC motor drive. Along with the proper PWM technique, the knowledge of back EMF waveform is obtained and the switching is done accordingly. This is expected to provide a good running performance with improved power quality. The overall block diagram of the proposed scheme is shown in Fig. 1.

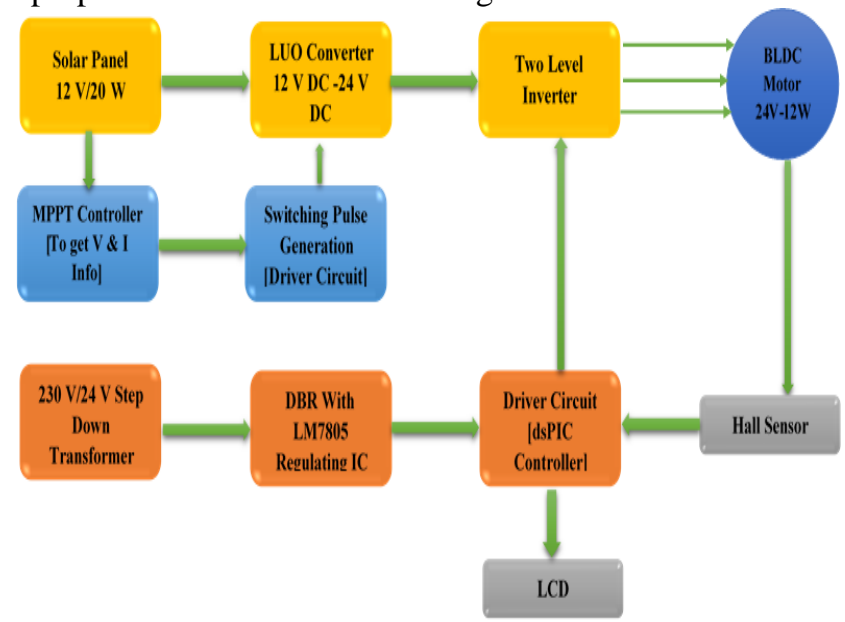

Fig. 1. Overall Block Diagram of the Proposed Scheme
The PV powered LUO converter switches are trigeered based on Maximum Power Point Tracking (MPPT) technique. In this way, the panel voltage and current are measured instant by instant and the firing pulses are generated at maximum power point. dsPIC driver is used for producing firing pulses. Hall sensors employed on the rotor senses its positions and keeping them as reference value, the stator windings are excited via two level inverter. As stated above, totally six switching sequences are generated and executed. The overall image of the hardware module is shown in Fig. 2.

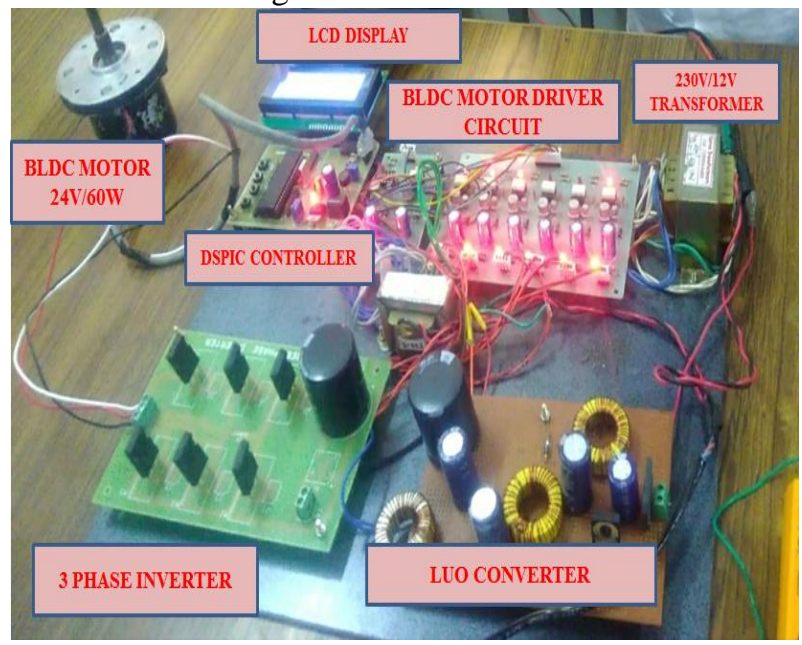

Fig. 2. Hardware Module of the Proposed Scheme

\section{RESULT ANALYSIS}

The drive was evaluated for different loading conditions and the results were observed. The gate pulse waveform for upper and lower switches of two level inverter is shown in Fig. 3 \&Fig. 4 respectively. The gate pulse waveform for LUO converter is shown in Fig. 5.

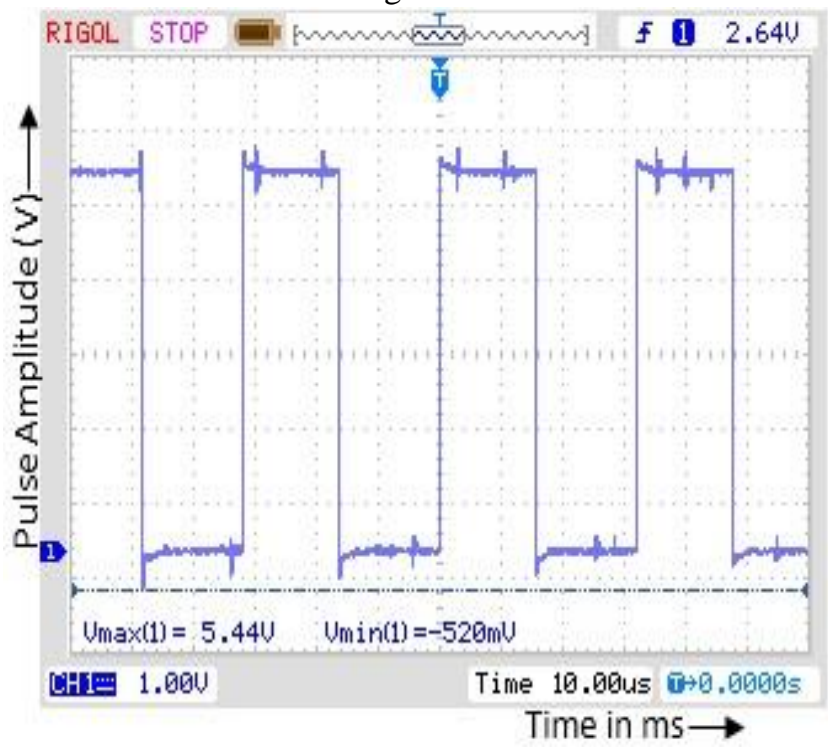

Fig. 3. Gate Pulses for Upper Switch 


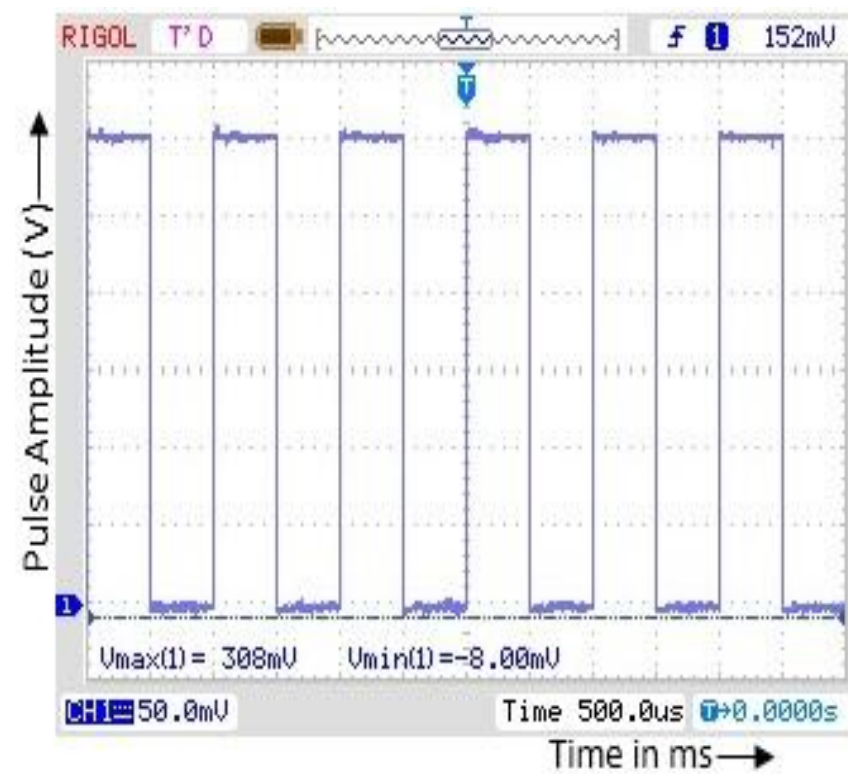

Fig. 4. Gate Pulses for Lower Switch

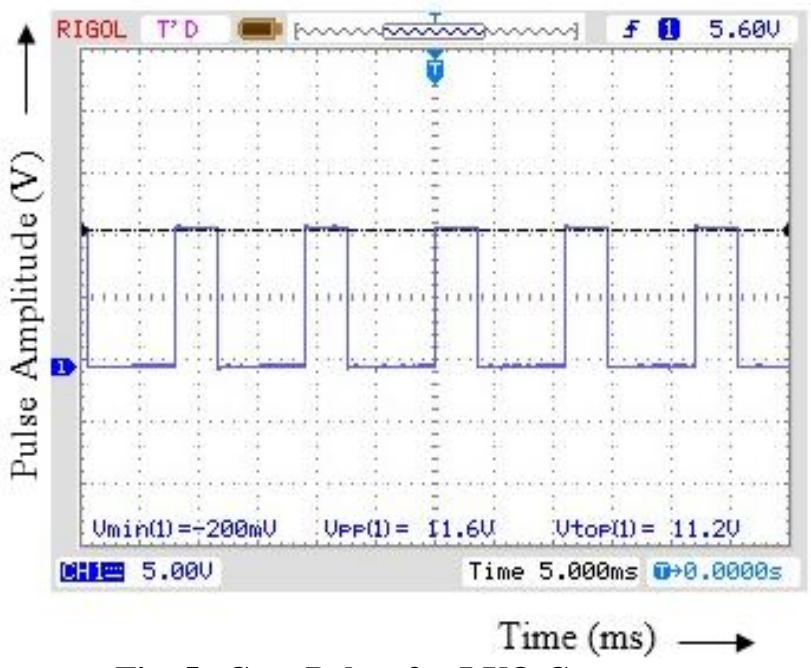

Fig. 5. Gate Pulses for LUO Converter

The back EMF waveforms of the BLDC motor for different phases are shown in Fig. 6,7 \& 8 respectively.

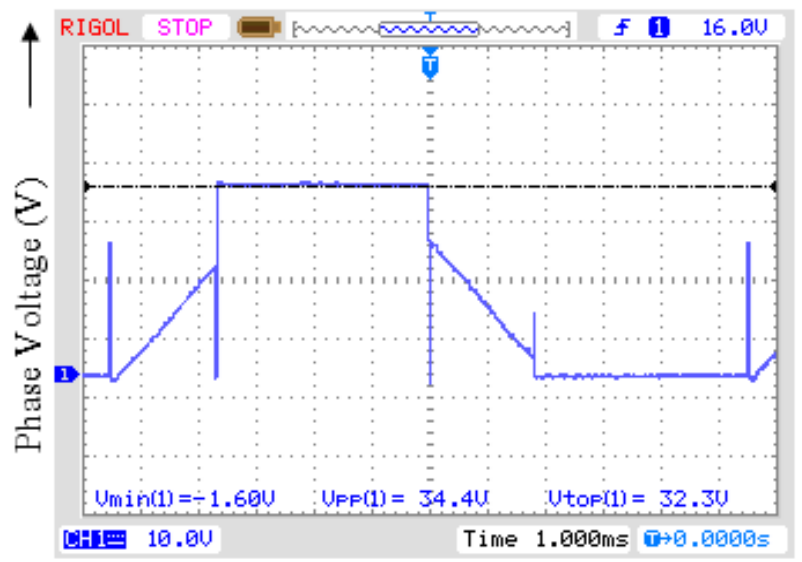

Time (ms) $\longrightarrow$

Fig. 6. Back EMF Waveform (Phase A)

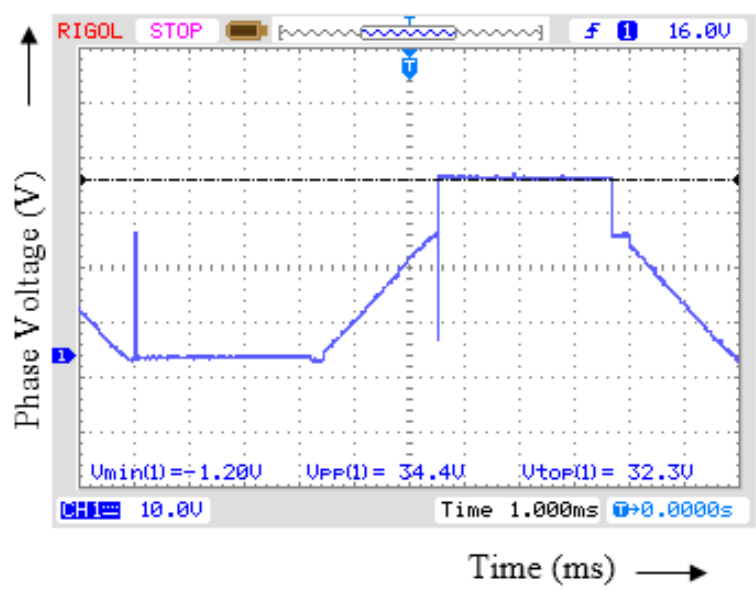

Fig 7. Back EMF Waveform (Phase B)

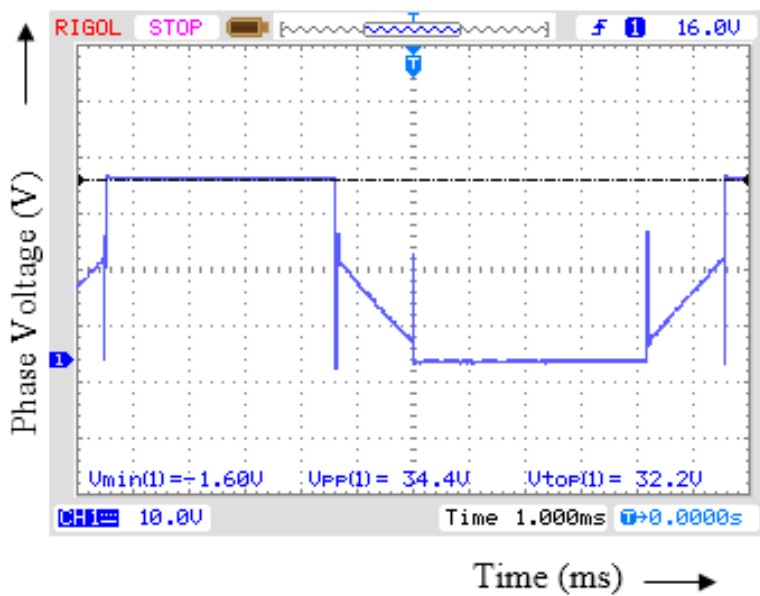

Fig 8. Back EMF Waveform (Phase C)

It is found that, irrespective of different operating speed conditions, the power factor is maintained at a constant value, which is shown in Fig. 9.

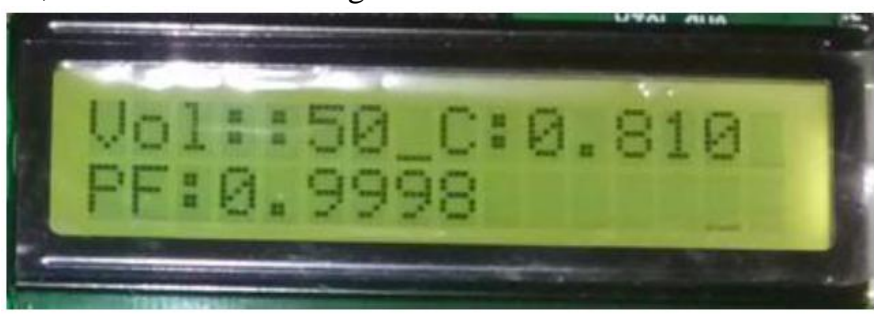

Fig 9. Power Factor Display

\section{CONCLUSION}

In the proposed work, the BLDC motor is powered with the help of renewable energy system with front end LUO converter topology. Compared to diode bridge rectifier or bridged type converter fed BLDC motor type, this method gives good results in terms of cost, acoustic noise, less ripple, improved supply power factor. The hardware has been developed and the results obtained show its suitability especially for agricultural irrigation purpose.

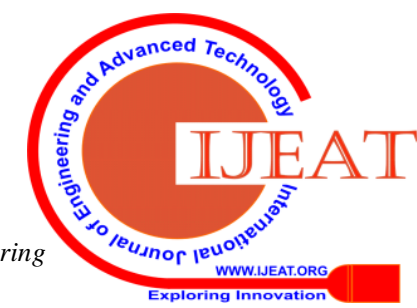




\section{REFERENCES}

1. Arunkumar, S. and Catherine, J.P., 2018. A Novel Method of Power Quality Improvement in BLDC Motor Using Cascaded H-Bridge MLI Topology. In Intelligent and Efficient Electrical Systems (pp. 107-115). Springer, Singapore.

2. Chuang .H. S and Ke. Y.L, (2009), "Analysis of Commutation Torque Ripple Using Different PWM Modes in BLDC Motors", IEEE Transactions on Industrial Electronics, Vol. 22, no. 3, pp.2213-2229.

3. Zhang.X.F and Lu.Z.Y, (2006) "A New BLDC Motor Drives Method Based on BUCK Converter for Torque Ripple Reduction", IEEE Transactions on Power Electronics, vol. 16, no. 4, pp.1880-1895.

4. Arunkumar, S., and S. Thangavel. "A review paper on torque ripple reduction in brushless DC motor drives with different multilevel inverter topology." Indonesian J ElectrEng 13.1 (2015): 65-75. Fang. J, Li. H and Han. B, (2012) "Torque Ripple Reduction in BLDC Torque Motor with Non-Ideal Back EMF", IEEE Transactions on Power Electronics, vol. 27, no. 11, pp.4630-4637.

5. Bhim Singh and VashistBist, (2013) "Improved Power Quality Bridgeless Cuk Converter fed Brushless DC Motor Drive for Air Conditioning System", IET Power Electronics, vol. 6, no. 5, pp.902-913.

6. THOTTUNGAL, RANI. "AN EXPERIMENTAL INVESTIGATION OF PFC BLDC MOTOR DRIVE USING BRIDGELESS CUK DERIVED CONVERTER." International Journal of Pure and Applied Mathematics 116.11 (2017): 141-149..

7. VashistBist and Bhim Singh, (2014) "An AdjustableSpeed PFC Bridgeless Buck-Boost Converter-Fed BLDC Motor Drive", IEEE Transactions on Industrial Electronics, Vol. 61, no. 6, pp.2665-2677. 